ISSN 2332-287X

\title{
Death of An Inmate Following Multiple Suicide Attempts With Razor Blade: A Case Report
}

Tokdemir $\mathrm{M}^{1}$, Kafadar $\mathrm{H}^{2 *}$, Turkoglu $\mathrm{A}^{1}$

${ }^{1}$ Department of Forensic Medicine, Faculty of Medicine, Firat University, Elazig, Turkey.

2 Regional Center, Council of Forensic Medicine Ministery of Justice, Elazig, Turkey.

Aim: To evaluate a prisoner died because of suicide attempt by using rasor blade.
Case: A 28 year old male prisoner was found dead lying in a pool of blood inside prison lavatory.
Result: On his right side of the neck there were multiple incisions produced by single-use razor blade. This was interesting in a way
that the incisions were made by his right hand because his left hand was in plaster. The prisoner died because of hemorrhagic shock
secondary to blood loss due to great vessel injury.
Conclusion: We believe that psychiatric support and constant surveillance of the prison grounds are necessary to decrease or elimi-
nate inmate suicides.
Key Words: Suicide; Prisoners; Razor Blade.

\section{*Corresponding Author:}

Hüseyin Kafadar,

Regional Center, Council of Forensic Medicine, Ministery of Justice,

Elazig, 23119, Turkey.

Tel: +90 05069091166

E-mail:kafadar23@yahoo.com

Received: December 16, 2013

Accepted: January 23, 2014

Published: January 25, 2014

Citation: Tokdemir M, Kafadar H, Turkoglu A (2014) Death of an Inmate Following Multiple Suicide Attempts with Razor Blade: A Case Report. Int J Forensic Sci Pathol. 2(1), 13-15. doi: http://dx.doi. org/10.19070/2332-287X-140005

Copyright: Kafadar $\mathbf{H}^{\circ}$ 2014. This is an open-access article distributed under the terms of the Creative Commons Attribution License, which permits unrestricted use, distribution and reproduction in any medium, provided the original author and source are credited.

\section{Introduction}

Suicide rate among inmates is higher than the general population. Socioeconomic and psychological problems trigger the idea of suicide. Methods of suicide vary among populations. Slashing the throat is a well-defined method of suicide [1],

That is frequently committed by a knife [2], occasionally chainsaw [3], band [4] or hand saw[5]. As a tool usage of razor blade is considerably difficult way to commit suicide and therefore in the literature there are only a handful of cases [6].

\section{Case Report}

Our case, a 28 year old male, $1.82 \mathrm{~cm}$ tall, weighing $70 \mathrm{~kg}$, convicted of grievous bodily harm died of a wound on the right side of his neck made by a sharp object. In his medico-legal documents, it was noted that he injured his left forearm and abdomen with a razor blade 3 days ago. He was found dead in the prison toilet with multiple incisions on the right side of the neck produced by single-use razor blade that severed the great vessels.

During the post-mortem examination, right side of the neck, right shoulder, thorax, right upper extremity and right hand were stained with blood. On the left side of his neck, there were superficial cuts, the longest measuring $3.5 \times 0.1 \mathrm{~cm}$, running obliquely and involving the subcutaneous tissues. Left hand and forearm was in plaster. When the plaster was opened a $6 \mathrm{~cm}$ long sutured wound was observed at the left wrist that appeared a few days old. There were two surgical incisions made to intervene the initial wound. The lateral incision was $6 \mathrm{~cm}$ long and the medial incision was $5 \mathrm{~cm}$ long, both running parallel to the long axis of the forearm (Figure 1). Between the thyroid gland and the upper part of the right shoulder, there was an $11 \times 5 \mathrm{~cm}$ lesion induced by intersection of 3 cuts (Figure 2). The wound lips were smooth and the incision involved the skin, subcutaneous tissues, muscles, internal and external jugular veins and the internal carotid artery (Figure 3). It was concluded that the individual died of external hemorrhage and hemorrhagic shock secondary to great vessel injury.

\section{Discussion}

In many countries suicide among inmates constitutes a major problem that needs to be solved as well in Turkey [7-12]. In Finland and United Kingdom, suicide was three times more common among inmates than normal population [12-16]. Hanging at night was the most common method to commit suicide among inmates [14].

Our case used a rare method that cut his neck with a razor blade. Tendency to commit suicide is found to be higher in the first days, weeks and months of incarceration [15]. In agreement with this finding, our case committed suicide three months into his sentence. The lesion that caused the mortality was on the right side of the neck produced by the union of multiple incisions 
Figure 1. Incision at the left wrist.

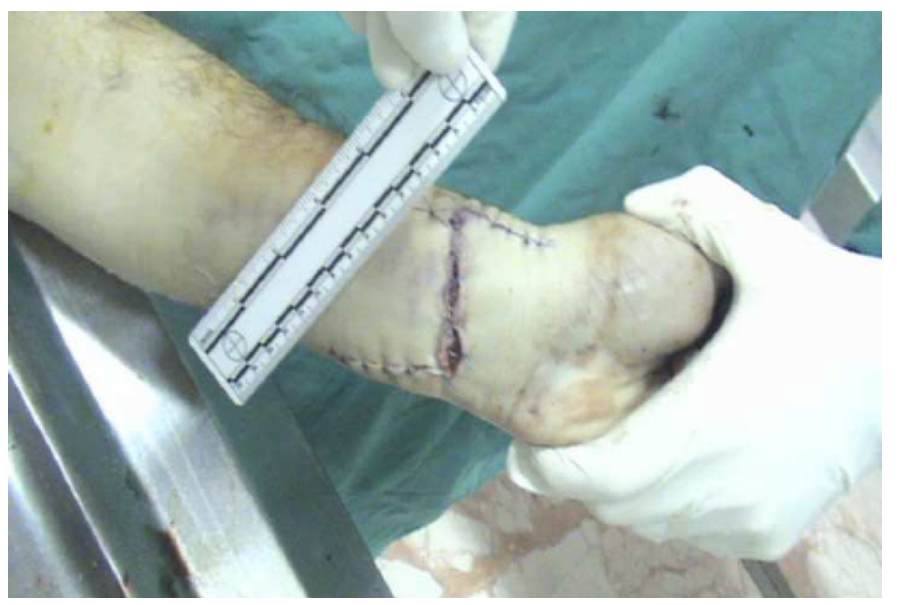

Figure 2. The incision on the right side of the neck and blood stained regions.

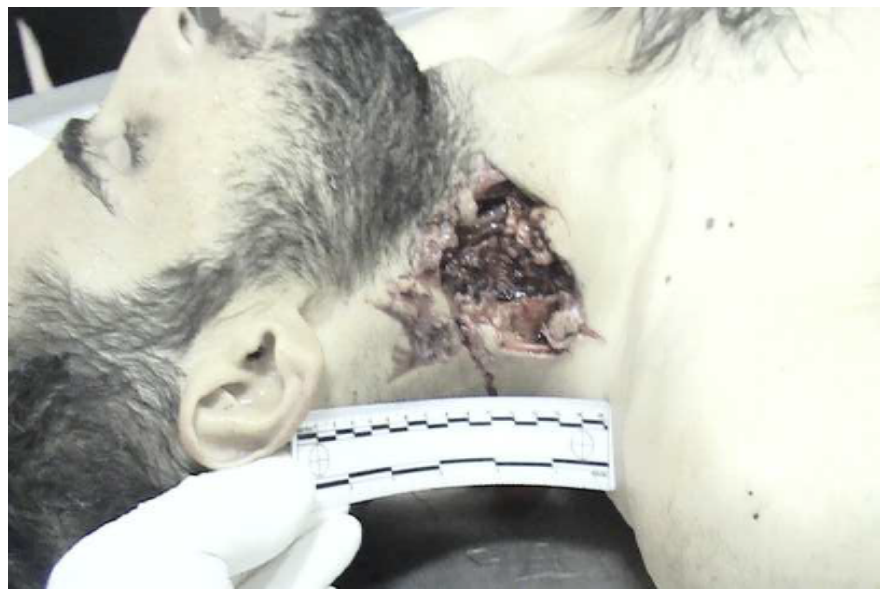

Figure 3. Lacerated carotid artery is shown

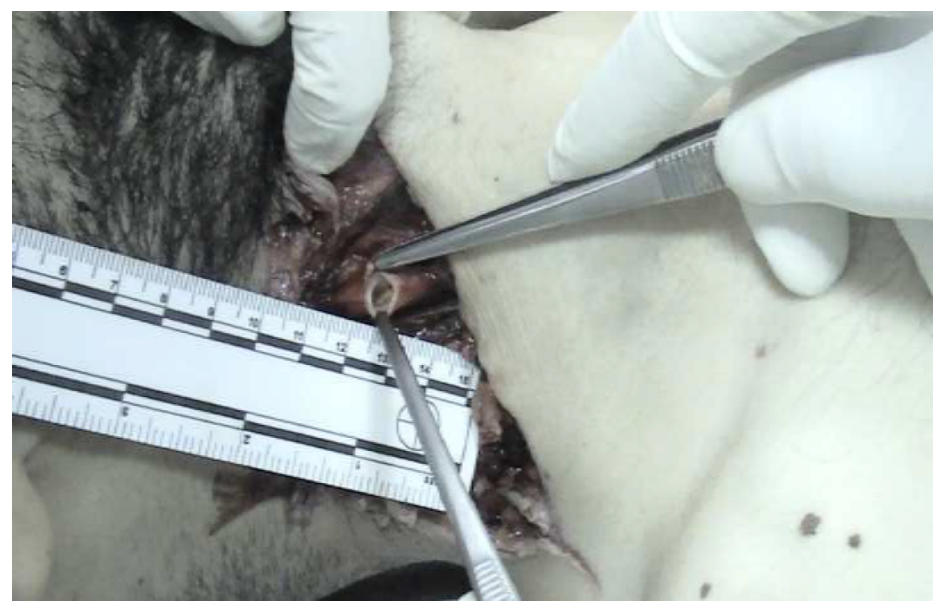

that severed the great vessels. His suicide attempt 3 days ago not only proves his determination to carry out his intention but also indicate that close follow-up, care and psychiatric support were deficient to prevent inmate suicides. In suicide cases, the lesion is usually on the left side of the neck, following an oblique course, when committed by slashing the neck with a sharp object. Incisions crossing the midline or those with a horizontal course are very rare[15]. Our case was interesting in a way that his left hand was in plaster and, therefore, he used his right hand but the lesion was on the right side of his neck.

Improving prison conditions, preventing inmates' access to instruments that can be used for suicides, psychiatric support and constant surveillance of the prison grounds are necessary to decrease or eliminate inmate suicides.

\section{References}

[1]. Keith MA, Taylor's Principles and Practice of Medical Jurisprudence, 13th ed., Churchill Livingstone, 1984, p. 238.

[2]. Abdullah F, Nuernberg A, Rabinovici R, Self-inflected abdominal stab wound. J Injury. 2003; 3435- 39.

[3]. Betz P and Eisenmenger W, Unusual suicides with electric saws. Forensic Sci. Int. 1995; 30; 75(2-3):173-9.

[4]. Clark SP, Delahunt B, Thomson KJ and Fernando TL, Suicide by band saw. Am. J. Forensic Med. Pathol. 1989; 10(4): 332-334.

[5]. Betz P and Eisenmenger W, Suicidal attempt with a handsaw. Med. Sci. Law. 1997;37(4):353-355.

[6]. Jovic R, Suicidal knife injuries of the neck. Med. Pregl. 1996;49 (7-8), 308-312.

[7]. Polson CJ, Gee DJ, Knight B, The Essentials of Forensic Medicine, fourth ed., Pergamon, 1985, p. 114.

[8]. Topp DO, Suicide in prison. Br. J. Psychiatry 1979; (134): 24-27.

[9]. Hayes LM and Darkness closes in... A national study of jail suicides. Crim. Justice Behav. 1983; (10): 461-484. 
[10]. Backett S, Suicides in Scottish prisons. Br. J. Psychiatry 1987; (151):218221.

[11]. Dooley E, Prison suicide in England and Wales, 1972-87. Br. J. Psychiatry. 1990; (156):40-45.

[12]. Liebling A, Suicides in Prison, Routledge, London and New York, 1992.

[13]. Joukamaa M, Prison suicide in Finland 1969-1992, Forensic Sci. Int. 1997; (89):167-74.

[14]. Dooley E, Prison suicide in England and Wales, J. Psychiatry 1990;
(156):40- 45 .

[15]. Rautji R, Behera C, Kulshrestha P, Agnihotri A, Bhardwaj DN and Dogra TD, An unusual suicide with a safety razor blade-a case report Forensic Sci. Int 2004;(142): 33- 35.

[16]. Joukamaa M, The mortality of released Finnish prisoners; a 7 year followup study of the WATTU project, Forensic Sci. Int. 1998;(96): 11-19. 